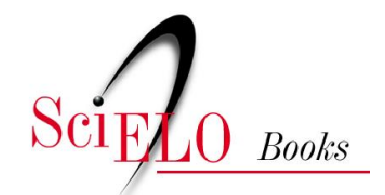

\title{
Utopia, ainda que tardia
}

\author{
Cidoval Morais de Sousa
}

\section{SciELO Books / SciELO Livros / SciELO Libros}

SOUSA, C. M., org. Utopia, ainda que tardia. In: Um convite à utopia [online]. Campina Grande: EDUEPB, 2016. Um convite à utopia collection, vol. 1, pp. 15-28. ISBN: 978-85-7879-488-0. Available from: doi: 10.7476/9788578794880.0001. Also available in ePUB from: http://books.scielo.org/id/kcdz2/epub/sousa-9788578794880.epub.

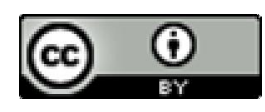

All the contents of this work, except where otherwise noted, is licensed under a Creative Commons Attribution $\underline{4.0 \text { International license. }}$

Todo o conteúdo deste trabalho, exceto quando houver ressalva, é publicado sob a licença Creative Commons Atribição 4.0.

Todo el contenido de esta obra, excepto donde se indique lo contrario, está bajo licencia de la licencia Creative Commons Reconocimento 4.0. 


\section{UTOPIA, AINDA QUE TARDIA}

Cidoval Morais de Sousa ${ }^{1}$

A obra O fim da Utopia, de Russell Jacoby, (2001) é sintomática: a falta de uma visão de futuro tem paralisado a esquerda, de tal modo, que os intelectuais e críticos já não se mostram capazes de imaginar uma outra sociedade. Entramos "na era da aquiescência": estruturamos nossas vidas, nossas famílias e nossas carreiras com muito poucas expectativas. Sumiu do mapa, na sua asserção, "uma certa noção de utopia, a ideia de que o futuro pode transcender o presente". Falar de utopia hoje é correr riscos, uma vez que "poucos são os que encaram o futuro como algo mais que uma réplica do presente". Poucas coisas, segundo ele, parecerão mais "quixotescas ou irrelevantes", na contemporaneidade, do que defender o "impulso utópico."

Exagero ou não, o certo é que, como afirma Tamayo (2012), não vivemos tempos propícios à utopia. Vivemos um tempo de concessões, de silêncio, de preferência por ajustes, adequações, reformas. Um tempo com os pés num "cruzamento de sombras", que vêm do passado e do futuro (SANTOS, 1998). Não temos certeza se já fomos ou se ainda seremos. E o que seremos. Tempos

1 Professor da Universidade Estadual da Paraíba e Coordenador Geral da Coleção Um Convite à Utopia. Email: cidoval@gmail.com 
de apatia e indiferença. Tempos de silêncio. Em certa medida, aderimos (ou assumimos) à tese segundo a qual não há mais cura para as síndromes decorrentes da modernidade. Dentre elas, a mesmice crônica (mais do mesmo), a auto-suficiência (podemos e temos tudo e mais um pouco) e a auto-referência (é assim que se faz). Tais síndromes, em nosso ver, se espalham veloz e eficientemente por diferentes canais (mídia, por exemplo), contaminando o tecido social, ampliando as vozes dos que já se renderam ao "tudo está bem como está", e desqualificando os que insistem em contrariar o establishment reabilitando, criticamente, o ideal utópico.

As utopias, historicamente, emergem em tempos de crise, propondo, quase sempre, uma inversão da realidade: a paz em oposição à guerra; liberdade e democracia em tempos de ditadura; uma cidade feliz em tempos de caos urbano; a sustentabilidade do 'bem viver' em oposição ao desenvolvimento desigual e combinado, marca registrada do capitalismo contemporâneo; educação conectada com a vida, em tempos de 'escola sem partido'; ciência e tecnologia à serviço da vida, em contraposição à morte que sai dos laboratórios (de nossas universidades, inclusive), maioria das vezes comissionada com recursos públicos; uma mídia cidadã em tempos de mídia golpista (casos recentes no Brasil, Argentina e Venezuela).

Muitos já tentaram decretar a morte da utopia, ou a sua inutilidade. Ora, por ser confundida com alienação; ora, por não fazer sentido num mundo já locupleto e satisfeito com as 'maravilhas' da modernidade. Em 500 anos de experiência o conceito "caiu de conceito", foi renegado, teve seu tempo de deserto, foi ao inferno, mas, talvez contando com a proteção de seu criador, Thomas Morus, que virou santo depois de ser preso e executado por contrariar à Monarquia Inglesa, pode ser que se reabilite e volte a 
apontar caminhos. Esta coleção tem como proposta fundamental contribuir para essa reabilitação.

Seguindo Fátima Vieira (2012, p. 8), quem fala de utopia em tempos de crise "assume a função de timoneiro de um navio (como o que Saramago descreve em O Conto da Ilha Desconhecida) que transporta homens e mulheres com as mãos nos olhos, a servirem de pala, perscrutando o horizonte, na expectativa de serem os primeiros a gritar "Terra à vista" - e que acabam por perceber que a utopia está na procura, num processo de demanda que tem o efeito positivo de nos levar sempre mais além, de não nos deixar ficar parados"

\section{A Utopia, 500 anos}

Como já foi sinalizado na Nota Técnica dos Editores, esta Coleção se articula no contexto das comemorações dos 500 anos de publicação de $A$ Utopia, de Thomas Morus. Trata-se de um clássico da literatura mundial, publicado em 1516 e que continua a ser lido, discutido e analisado por sua agenda de críticas à acumulação perversa, à exploração do homem pelo homem e pela defesa incisiva de que o bem comum é mais valioso que o bem individual, e que a propriedade privada é o cerne das desigualdades sociais. A palavra "Utopia” geralmente é vinculada a algo irrealizável ou que não existe em lugar nenhum. Entretanto, pode, também, ser associada tanto a "nenhum lugar" (considerando a união do advérbio grego "ou" - que significa "nenhum" - ao substantivo "topos" - que significa "lugar" - "outopia"), quanto a um lugar feliz, um lugar onde se vive bem (considerando a união do advérbio "eu" - feliz - ao mesmo substantivo - "eutopia"). Utopia como "lugar nenhum" é, de fato, um lugar irreal; já como "lugar feliz", tem uma exigência ética e política que preside a elaboração deste sonho "utópico". 
No mundo de A Utopia, tudo é de todos. Sua mensagem, na compreensão de muitos leitores, acadêmicos e não acadêmicos, militantes de diferentes tendências à esquerda (nós editores incluídos), continua fazendo sentido, especialmente neste momento de aguda crise, com ameaças reais a conquistas históricas, como no caso brasileiro: há alternativas ao que está instituído. Lançado em Latim em 1516, é, como afirmam vários autores, um texto fundamental do humanismo. Numa época de monarquias, de colonização com extermínio da gente e dos recursos naturais do chamado Novo Mundo, a ilha de A Utopia apresenta um sistema político baseado na vontade do povo, numa forma de fazer política em que todos podem participar. Não é o mais perfeito dos lugares-sistemas (há flagrantes de totalitarismo), mas, considerando o contexto, representava, naquele momento, uma reforma singular nas estruturas políticas, econômicas e culturais da época.

Há quem afirme que da mesma maneira que Morus olhou para as desigualdades de seu tempo e apontou caminhos para um mundo novo, os reformistas sociais do século XIX fizeram o mesmo. A ideia de uma sociedade igualitária teria inspirado obras como as de Pierre Proudhom (1809-1865), Charles Fourier (17721837), Robert Owen (1771-1858) e Saint-Simon (1760-1825), classificados como "socialistas utópicos" por Marx (1818-1883), que ofereceu, em contraposição, o "socialismo científico". Não foi o primeiro texto da história sobre um ideal utópico (apesar de a palavra utopia ter sido criada por ele), entretanto inaugurou uma tradição de obras com agenda comum: projetos alternativos para uma sociedade em crise (Nova Atlântida, de Bacon; Cidade do Sol, de Campanella; Christianopolis, de Valentin Andrea; Oceana, de James Harrington, dentre outros). 


\section{Sobre o conteúdo deste volume}

Os ensaios para o primeiro volume de Convite foram selecionados levando-se em consideração os seguintes critérios: (1) textos importantes para compreender o contexto de produção e significado histórico da obra de Morus e sua atualidade; (2) produções que problematizassem o conceito de utopia numa perspectiva de reabilitação crítica; (3) textos que oferecessem, a partir de temas críticos da contemporaneidade, como cidades, comunicação, ciência, tecnologia e educação, leituras inovadoras, provocadoras, disseminadoras de utopias. Diante da quantidade e qualidade do material inédito recebido, graças a "viralização" da convocatória de textos nas redes sociais e das propostas de republicações postas à mesa, a Comissão decidiu por uma publicação mista, que contemplasse o clássico e o emergente. ${ }^{2}$ Com exceção do texto de Mannheim, $A$ Mentalidade Utópica, os ensaios republicados (4 no total) estão todos, em sua versão original, disponibilizados na Net, em acesso livre. Os demais textos são inéditos, foram escritos especialmente para a Coleção. A republicação, neste espaço, de textos considerados seminais para a reflexão sobre utopia, utópicos, utopias, na compreensão dos editores, reúne o que está disperso e torna possível novas leituras, diálogos, aproximações, críticas, atualizações, numa multiplataforma de esperanças.

O ensaio Notas sobre Utopia, de Marilena Chaui, uma das mais conhecidas e respeitadas filósofas brasileiras, seja por sua provocativa produção acadêmica, seja por sua militância política em defesa

2 A Convocatória continua aberta: ensaios de até 30 páginas sobre o tema Utopia, em suas diferentes dimensões, em documento do word, fonte arial, tamanho 12, intervalo entrelinhas 1,5. A normalização deve seguir padrão ABNT. Email para contato: cidoval@gmail.com; eduepb@uepb.edu.br 
da democracia e de um mundo mais justo, publicado em 2008 na Revista Ciência e Cultura, Editada pela SBPC, e já disponível na Net (ver endereço no próprio texto), abre a sequência de textos selecionados para o que estamos chamando de volume introdutório da Coleção Convite. Expõe de forma precisa os significados da palavra Utopia, título da obra seminal de Thomas Morus (1477[8?]-1535) e apresenta uma síntese das principais características da utopia em seu movimento histórico. Segundo Chaui, a utopia é (1) normativa (propõe um mundo tal como deve ser, em oposição ao mundo que se tem); (2) é sempre totalizante e crítica do existente; (3) é a visão do presente sob o modo da angústia, da crise, da injustiça, do mal, da corrupção e da rapina, do pauperismo e da fome, da força dos privilégios e das carências, ou seja, o presente é percebido como violência; (4) é radical (busca a liberdade e a felicidade individual e pública); (5) é uma maneira peculiar da imaginação social, que busca combinar o irrealismo, ou a crença na total transparência do social, e o realismo, por meio da apresentação dos mínimos detalhes da nova sociedade; (6) é um discurso cujas fronteiras são móveis, ou seja, a utopia pode ser literária, arquitetônica, religiosa, política. O utopista, na concepção de Chaui, é um revolucionário ou um reformador consciente do caráter prematuro e extemporâneo de suas ideias que, por isso, não podem ser postas como um programa. O texto inclui ainda uma leitura contextualizada da obra de Morus, sua repercussão e influência ao longo desses 500 anos e um balanço das críticas, incluindo as feitas por Marx e Engels.

Tomo aqui emprestado de Ozaí da Silva ${ }^{3}$ o seguinte trecho: "As ideologias mobilizam indivíduos e multidões, alimentam intolerâncias, intentam conservar ou transformar sociedades, produzem

3 Resenha publicada na revista Espaço Acadêmico, Edição Especial 08 anos, e disponível em: http://www.espacoacademico.com.br/096/96esp_ozai.htm 
guerras e revoluções. Qual seria a fonte dessa força imensa que se dissemina e conquista corações e mentes em povos de culturas e realidades tão díspares? Será porque expressam utopias? Ideologias e utopias são semelhantes, nomes diferentes para os mesmos fenômenos políticos e sociais? Se as ideologias sobrevivem ao passar dos anos e vivificam nos homens e mulheres do tempo presente, mesmo quando são declaradas mortas, será que vivemos uma época em que a utopia se exauriu?" Buscamos, a partir dessas provocações, inserir o leitor de Convite nesse debate aberto por Karl Mannheim (1893 -1947), em seu livro de 1929, Ideologia e Utopia, publicado no Brasil pela Zahar Editores em 1968. Selecionamos dessa obra clássica o capítulo IV, intitulado A Mentalidade Utópica, do qual destacamos que as utopias transcendem a situação social, pois orientam a conduta para elementos que a situação, tanto quanto se apresente em dada época, não contém. Mas elas, como bem acentua o autor, não são ideologias, isto é, não são ideologias na medida e até o ponto em que conseguem, através da contra-atividade, transformar a realidade histórica existente em outra realidade, mais de acordo com suas próprias concepções.

No ensaio Utopias por um mundo melhor, publicado na Revista de História Saeculum, em 2004, disponível na Net (endereço de acesso indicado no próprio ensaio), Adalmir Leonídio, pesquisador com destacada produção no campo dos estudos sociais da utopia, a proposição que ganha força no texto é que "a imagem da utopia como mero sonho, fantasia ou evasão da realidade, não parece mais ser aceita pelos estudiosos do tema", e que "tampouco ela parece revelar-se exclusivamente através do seu conteúdo revolucionário." Segundo ele, desde Platão, houve um número muito grande de utopias, correspondentes aos diferentes contextos em que tais obras emergiram. $\mathrm{O}$ autor, nesse ponto, provoca os leitores com uma pergunta: o que permite então falar em utopia 
como um dado conceito, uma realidade ou conteúdo que perpassa as diferentes manifestações literárias de natureza utópica? Sua resposta: a mundividência utópica revela uma série de elementos comuns: o modelo e a realização do modelo; a busca da unidade social e de uma sociedade harmônica e concorde, onde o todo é mais importante que as meras partes constituintes e conflitantes; enfim, a busca de uma ordem perfeita. Cada utópico, afirma Leonídio, em diferentes momentos, elaborou seus conteúdos de forma distinta: Platão, através de uma perfeita hierarquização das funções sociais; Morelly através de uma imitação da ordem natural por parte da ordem social; Babeuf através de uma radicalização do conteúdo igualitário dos princípios da Revolução Francesa, e assim por diante. E Leonídio finaliza com uma reflexão importante sobre a atualidade da utopia: o sentido mais importante e atual talvez seja o não conformismo, a não aceitação de nenhuma realidade como definitiva, a não ser aquela que eleve ao mais alto grau as potencialidades humanas, isto é, o otimismo de perspectiva e o ideal universalista do homem. Conforme a mensagem de Cândido, personagem de Voltaire, hoje repetida entre aqueles que ainda acreditam em alguma forma de utopia, "um mundo melhor é possível".

Num ensaio produzido exclusivamente para esta coletânea, Nicole Aguilar Gayard, Mylène Tanferri Benjamin Raimbault, e Zara Mirmalek buscam renovar a atenção sobre as utopias, situando-as no tempo presente, nas práticas quotidianas, nos movimentos de reprodução ou de contestação social. Argumentam que as utopias podem ser percebidas nas práticas a partir das quais se pensam e se buscam soluções para os problemas sociais. Partem do conceito de heterotopia (elaborado por Foucault), que apresenta uma perspectiva situada do pensamento utópico, e incorporam a concepção dos imaginários sociotécnicos (desenvolvida por Sheila Jasanoff 
e Sang-Hyun Kim) a fim de entender os desejos de reforma como uma característica das sociedades presentes. Com base nestes conceitos, as autores constroem uma releitura sobre o reavivamento das utopias nas políticas contemporâneas. A perspectiva conceitual adotada, conforme as autoras, permite introduzir casos específicos, que retratam coletivos trabalhando em espaços e tempos situados, recuperando a importância dessas dimensões para suas vidas e articulando diferentes versões de ordenamentos sociais ou demostrando implicitamente a importância da interação entre significados e lugares. Os exemplos foram buscados em movimentos no Brasil (ocupação de escolas por estudantes em São Paulo), França (transformação do uso do espaço no aeroporto em Notre Dame des Landes), Suíça (novas formas de uso do espaço via habitações cooperativas) e nos Estados Unidos / China (reprodução de cidades ocidentais na China), pelos quais utopias foram criadas, transportadas e reformuladas.

O texto de Alberto Acosta, publicado, originalmente, na coletânea Um Campeão Visto de Perto - Uma Análise do Modelo de Desenvolvimento Brasileiro, Editada pela Heinrich Böll Foundation, na Série Democracia (2012), pontua que no contexto das discussões pós-desenvolvimentistas se multiplicam os esforços por uma reconstrução e inclusive pela superação da base conceitual, das práticas, das instituições e dos discursos do desenvolvimento. Nesta situação, segundo ele, há que se superar inclusive as visões heterodoxas, que enfocavam "desenvolvimentos alternativos", quando é cada vez mais necessário gerar “alternativas ao desenvolvimento". É nesse contexto que ele apresenta o Buen Vivir como uma oportunidade para construir coletivamente novas formas de vida. O Buen Vivir, diz ele, não é uma originalidade nem uma novidade dos processos políticos do início do século XXI nos países andinos. Nem é uma espécie de superstição ou poção 
mágica para todos os males do mundo. É parte de uma grande busca de alternativas "de vida forjadas no calor das lutas da humanidade pela emancipação e pela vida". A tarefa de reconstrução/ construção do Buen Vivir é, conforme acentua Acosta, descolonizadora (e despatriarcalizadora). Estabelece definitivamente uma cosmovisão diferente da ocidental ao surgir de raízes comunitárias não capitalistas e rompe, igualmente, com as lógicas antropocêntricas do capitalismo como civilização dominante e também dos diversos socialismos realmente existentes até agora.

Por sua vez, os professores Antonio Roberto Faustino da Costa, Pedro Bergamo e Roberto Marden Lucena respondem ao presente Convite, legando-nos um ensaio inédito e provocador ao processo civilizatório e cultural, a propósito, além das fronteiras capitalistas. A utopia em questão: desalheamento educacional à objetividade lança um conjunto de representações de cinco realidades à indeclinável condição para delimitar objetos do pensar e do agir, a partir de práxis educativo-coletiva "sui generis" enquanto proposta/realização educacional, objeto primacial de uma educação dos próprios educadores: interação entre sustentador(es) e prole naturalmente ainda autoinsustentável; excedência de produção de pertença cultural-socialmente indefesa junto aos destinatários; distinção entre produzir e apropriar os inelimináveis resultados; limites; e sentido inequívoco do que é coletivo. "Constituir algo que perfaça inequívoco sentido do que é coletivo adentra mudança no complexo âmbito do processo inseparavelmente civilizatório e cultural; civilizatório enquanto materializável e cultural enquanto pensável", acentuam os autores. Objetividade, neste horizonte, torna-se condição sine qua non a uma utopia que precisa ser realidade e da realidade que não poderia existir sem ser utópica.

Slavoj Zizek, respeitado polemista no universo intelectual da contemporaneidade, em dois curtos textos, o primeiro 
(A verdadeira utopia) divulgado no Brasil pela Revista Filosofia - Conhecimento Prático, e o segundo (Crença na utopia é ainda a melhor forma de questionar a exclusão social), divulgado no blog cesarkiraly.opsblog.org, a única questão verdadeira hoje é: o capitalismo global contém antagonismos fortes o suficiente para impedir sua reprodução indefinida? Zizek, em resposta, aponta quatro antagonismos: a ameaça iminente de uma catástrofe ecológica, o caráter inapropriado da propriedade privada para designar a chamada "propriedade intelectual", as implicações socioéticas dos novos desenvolvimentos tecnocientíficos (especialmente na biogenética) e, por último, mas não menos importante, as novas formas de apartheid, os novos muros e as favelas. Para Zizek, a nova política emancipatória não será mais o ato de um agente social particular, mas uma explosiva combinação de diferentes agentes. O que se deve rejeitar, no seu entendimento, é a ideologia liberal-vitimista que reduz a política à decisão de se evitar o pior, a renunciar de todos os projetos positivos e perseguir a opção menos ruim - ou, como notou amargamente Arthur Feldmann, o escritor judeu vienense, o preço que usualmente pagamos para sobreviver é a própria vida. A verdadeira utopia hoje "é a de que seremos capazes de resolver nossos problemas com transformações modestas no sistema existente".

Valdir Jose Morigi, Solange Inês Engelmann, Luis Fernando Herbert Massoni e Ketlen Stueber, pesquisadores da Universidade Federal do Rio Grande do Sul, no inédito O reencantamento do mundo e acesso à informação: as potencialidades das Tecnologias de Informação e Comunicação (tics) na construção e reforço da Democracia destacam que o uso e apropriações das TICs como ferramentas de mediação das informações e de visibilidade, de crítica da realidade e de reivindicações dos direitos parece ter se ampliado. Para eles, ao mesmo tempo em que o acesso à informação é facilitado, também 
é possibilitado o acesso à produção da informação, uma vez que a nova forma de interação social permite que diversos sejam os agentes produtores de informação. Por outro lado, a formação de uma esfera pública questionadora e crítica se encontra ausente, o que contribui com a tentativa de massificação e instrumentalização da opinião pública e busca de legitimidade por parte dos Estados e governos descomprometidos com a democracia. A construção de conteúdos solidários e que promovam a cidadania já são praticados no ciberespaço e em algumas mídias tradicionais, mas ainda de modo insuficiente. Torna-se, portanto, inquestionável que os meios de comunicação sejam capazes de produzir os conteúdos das informações de maneira autônoma, sem que sejam regidos pela lógica do mercado. Para os autores, refletir acerca do reencantamento do mundo a partir das TICs, acreditar em suas possibilidades, por mais utópicas que possam parecer, significa reivindicar seus aspectos práticos e efetivos. A regulação dos meios de comunicação e informação é uma forma importante de tornar as TICs e o ciberespaço em espaços de sociabilidade voltados a construção e reforço da democracia e à cidadania planetária.

O professor José Marques de Melo, um dos mais respeitados pesquisadores da área de comunicação na América Latina, também em texto inédito, Mídia, Cidadania e Utopia no Brasil Cidadania e Utopia, defende a tese segundo a qual Utopia e Cidadania são conceitos que brotaram de uma mesma conjuntura histórica. São filhos diletos da modernidade e simbolizam produtos das "liberdades urbanas", responsáveis pelo "primeiro surto desenvolvimentista" europeu. A Cidadania foi sendo conquistada em meio a "tensões sociais" e "lutas de classes", gerando situações de incertezas, quando as Cidades começaram a sofrer ameaças regulatórias por parte dos Estados "modernos". Os detentores do poder, nos emergentes Estados nacionais, trataram de refrear o ímpeto da Cidadania, da 
mesma forma que os guardiões da doutrina, no precursor Estado multinacional (Igreja Católica), não hesitaram em frear o poder revolucionário da Imprensa. O autor faz, também, um balanço das pesquisas sobre Mídia e Cidadania e afirma que elas tem reforçando a esperança de que a utopia da mídia cidadã deixe de ser "quimera" (ilusão, fantasia), concretizando-se através de processos capazes de evidenciar que "o homem e a mulher encerram a potencialidade de ser sujeitos da história". Entretanto, diz ele, o caminho a percorrer demanda esforço, perseverança e determinação. Trata-se de batalha cuja vitória depende fundamentalmente da vontade política dos sujeitos que estão na vanguarda da sociedade política. Mas a sociedade civil e a comunidade acadêmica podem exercer influência, acelerando o processo através de estudos e reflexões capazes de sensibilizar e convencer os que tomam decisões nas estruturas de poder.

O professor Pedro de Andrade, do Instituto de Ciências Sociais da Universidade do Minho, Portugal, em contribuição exclusiva para Convite, discute as relações entre intelectuais e Web 2.0/3.0, que, segundo ele, ainda são problemáticas. A via aberta pelo intelectual comum necessita ser explorada: (a) tanto pela cooperação mais intensa entre os cidadãos no seio dos instrumentos colaborativos da social web e da social semantic web; (b) quanto por meio da construção de novas metodologias de reflexão e pesquisa que dissolvam o atual hiato entre o saber especialista e o conhecimento ordinário. Para esse debate, Andrade propõe uma reflexão na forma de 6 questões para contextualizar as utopias globalizadas no terceiro milênio: (1) o que é a utopia e o que significa a eventual utopia da utopia; (2) espaços sociais da vida diária (espaço público/púbico das democracias ou espaço púdico dos fundamentalismos?); (3) tempo social do quotidiano: restos, rastos ou rostos?; (4) esferas sociais de interesses: criação/invenção/inovação? 
Desejamos meros contatos sociais, ou novos contratos sociais?; (5) História e sociologia da globalização: omni-modernidades ou/e pluri-modernidades?; (6) Hibridologia nas multiculturas, interculturas ou transculturas? Será que vivemos num mundo onde existem múltiplos encontros mas também encontrões e recontros, por ex. as hibridações ou embates e debates, entre povos, entre espaços e tempos, entre tipos e fluxos de capital, entre políticas (policies e politics), entre interculturas e transculturas?

\section{Bibliografia}

JACOBY, R. O fim da utopia: política e cultura na era da apatia. Tradução de Clóvis Marques. Rio de Janeiro: Record, 2001

TAMAYO, J.J. Invitación a la utopía. Estudio histórico para tiempos de crisis. Trotta, Madrid, 2012, 304 págs.

SANTOS, B.S. Um discurso sobre as ciências na transição para uma ciência pós-moderna. Estud. av., Ago 1988, vol.2, no.2, p.46-71.

VIEIRA, F. Falar de utopia em tempos de crise. Via Panorâmica. Número Especial.,2012. 